Article

\title{
Low Power Modular Battery Management System with a Wireless Communication Interface
}

\author{
Roman Gozdur $^{1, *(\mathbb{D})}$, Tomasz Przerywacz ${ }^{2}$ (D) and Dariusz Bogdański ${ }^{3}$ \\ 1 Department of Semiconductor and Optoelectronics Devices, Lodz University of Technology, \\ Wólczańska Str. 211/215, 90-924 Łódź, Poland \\ 2 Faculty of Electrical, Electronic, Computer and Control Engineering, Lodz University of Technology, \\ Stefanowskiego Str. 18/22, 90-924 Łódź, Poland; t.przerywacz@gmail.com \\ 3 BTO Sp. z o.o., Fabryczna Str. 25, 90-341 Łódź, Poland; d.bogdanski@bto.pl \\ * Correspondence: gozdur@p.lodz.pl
}

Citation: Gozdur, R.; Przerywacz, T.; Bogdański, D. Low Power Modular Battery Management System with a Wireless Communication Interface. Energies 2021, 14, 6320. https:// doi.org/10.3390/en14196320

Academic Editor: Khay Wai See

Received: 1 September 2021

Accepted: 1 October 2021

Published: 3 October 2021

Publisher's Note: MDPI stays neutral with regard to jurisdictional claims in published maps and institutional affiliations.

Copyright: (c) 2021 by the authors. Licensee MDPI, Basel, Switzerland. This article is an open access article distributed under the terms and conditions of the Creative Commons Attribution (CC BY) license (https:// creativecommons.org/licenses/by/ $4.0 /)$.

\begin{abstract}
The paper concerns the design and development of large electric energy storage systems made of lithium cells. Most research advances in the development of lithium-ion battery management systems focus solely on safety, functionality, and improvement of the procedures for assessing the performance of systems without considering their energy efficiency. The paper presents an alternative approach to the design and analysis of large modular battery management systems. A modular battery management system and the dedicated wireless communication system were designed to analyze and optimize energy consumption. The algorithms for assembly, reporting, management, and communication procedures described in the paper are a robust design tool for further developing large and scalable battery systems. The conducted analysis of energy efficiency for the exemplary 100S15P system shows that the energy used to power the developed battery management system is comparable to the energy dissipated due to the intrinsic self-discharge of lithium-ion cells.
\end{abstract}

Keywords: lithium-ion batteries; energy efficiency; modular battery management systems; wireless communication protocols; low power electronics

\section{Introduction}

Sustainable development concerns many areas of our lives that combine into the domains of economy, society, and the environment. One of the sectors that significantly impacts these three domains is the electrical energy sector, which is particularly necessary to keep the present level of our society's life. Electrical energy is the most eco and valuable form of energy converted most efficiently into other forms, such as heat, kinetic, electromagnetic, potential, gravitational, or chemical energy. Modern electrical energy generation and conversion methods are relatively efficient and are ceaselessly being improved. A great challenge related to the use of electricity is its storage [1]. The distinct technological progress in the production of lithium cells also conduces to the development of energy storage systems [2].

Lithium cells are characterized by the highest specific energy density $\left(\mathrm{Wh} \cdot \mathrm{kg}^{-1}\right)$, volumetric energy density $\left(\mathrm{Wh} \cdot \mathrm{L}^{-1}\right)$, and the highest electrical activity of the electrodes [2,3]. Therefore, the electrodes and electrolytes of commercial cells are mostly made of materials based on lithium compounds [4,5]. Trade names and abbreviations are most often associated with the chemical composition of the cathode, which has a decisive influence on the technical parameters of the cells.

The cathodes of cells are made of $\mathrm{LiCoO}_{\mathrm{x}}(\mathrm{LCO}), \mathrm{LiNiO}_{2}(\mathrm{LNO}), \mathrm{Li}\left(\mathrm{Ni}_{1-x-y} \mathrm{Co}_{\mathrm{x}} \mathrm{Al}_{\mathrm{y}}\right) \mathrm{O}_{2}$ (NCA), $\mathrm{Li}\left(\mathrm{Ni}_{1-\mathrm{x}-\mathrm{y}} \mathrm{Mn}_{\mathrm{x}} \mathrm{Co}_{\mathrm{y}}\right)_{2}$ (NMC), $\mathrm{LiMn}_{2} \mathrm{O}_{4}$ (LMO), $\mathrm{LiFePO}_{4}$ (LFP) [6,7]. A more detailed review of the materials used in constructing lithium-ion (Li-Ion) cells can be found in references $[2,8]$. The electrode material has a critical influence on the value of the inter-electrode potential (cell voltage) and the energy density of a single cell. Currently, 
commercially available Li-Ion cells have a rated output voltage between $2.2 \mathrm{~V}$ (LTO) and $4.0 \mathrm{~V}$ (NMC, LMO), and the specific energy density ranging from $109 \mathrm{Wh} \cdot \mathrm{kg}^{-1}$ to $250 \mathrm{Wh} \cdot \mathrm{kg}^{-1}$ [1]. Advanced scientific studies in the field of alternative materials for batteries clearly indicate that also numerous other electrochemical compositions might be promising for future energy storage technologies [8-13].

The cell capacity depends on the overall dimensions of the cell and the applied materials. Based on the given application, cylindrical, prismatic, pouch, or custom cells are used. A single Li-Ion cell often has too little capacity and rated voltage as an independent power source [14]. Therefore, cells are connected either in series (nS) to increase the output voltage or in parallel $(\mathrm{mP})$ to increase the capacity and the rated output power [14-16]. The appropriate rated parameters, such as battery voltage and capacity, are often obtained by connecting cells in mixed series-parallel connection systems (nSmP). In this way, energy storage devices with an output voltage exceeding $400 \mathrm{~V}$ and a capacity of $50 \mathrm{kWh}$ are produced [17]. Large battery packs are made in a modular topology to simplify construction, operation, and maintenance [18-20]. Battery modules are the smallest, autonomous elements of a battery system.

Lithium technology also has numerous limitations. The charge and discharge state of a lithium battery must be strictly controlled, and both the operating and the storage temperature of cells are critical. Single Li-Ion cells used as power sources are equipped with autonomous electronic cell protection systems: PCM (Protection Circuit Module) or PCB (Protection Circuit Board). All the more, a large battery made of hundreds or even thousands of Li-Ion cells requires constant monitoring and balancing. The complexity of such a battery pack makes it necessary to use an electronic Battery Management System (BMS) being able to get data from every single cell and perform suitable further operations. Thus, BMSs have a crucial impact on battery systems' life cycle, safety, efficiency, and effectiveness. BMSs are also responsible for the prediction, evaluation, and control of complex operating parameters, such as State of Charge (SoC), State of Health (SoH), State od Power (SOP), State of Energy (SoE), State of Safety (SoS), State of Temperature (SoT) $[21,22]$.

BMSs are integral components of Li-Ion battery packs. They operate continuously and consume the energy accumulated in batteries. Increasing the efficiency of these devices, and thus reducing the energy losses in the battery system, extends the time of its staying in the idle state and the time of self-discharge to reach 100\% Depth of Discharge (DoD). This issue is significant both in battery packs of medium capacity and in battery packs where DoD is limited to maximize the lifetime of lithium cells [6]. The authors believe that by optimizing the communication algorithm and the employed scheme of interaction between the system modules, one can increase the energy efficiency of a battery pack without significant impact on the functionality of the BMS.

The paper presents the concept of a Modular Battery Management System (MBMS) with a new power-saving wireless communication interface. The main research interest was focused on the analysis and optimizing the energy consumption needed to power all the presented MBMS components.

\section{Battery Management Systems}

Battery systems are made as large packages or modular sets, and as mentioned shortly above, they require constant control and management for many reasons [23]. Li-Ion cells are very susceptible to damage if the cell voltage exceeds the operational range from $2.5 \mathrm{~V}$ to $4.2 \mathrm{~V}$ [6]. The cells achieve maximum cycle life only in a narrow operating DoD range from $20 \%$ to $40 \%$ [6]. Likewise, the optimal operating temperature range for Li-Ion cells is ranging from $0{ }^{\circ} \mathrm{C}$ to $55^{\circ} \mathrm{C}$. Increasing the operating temperature of cells above $55^{\circ} \mathrm{C}$ has a strongly negative influence on cells, causes a loss of cell capacity, shortens the lifespan, and reduces the total number of charge/discharge cycles [24-26]. In addition, a large number of cells used to increase the output voltage or capacity of the battery system reduces the 
reliability of the entire system since a damaged cell may either break an electrical circuit in a series connection or may cause an electrical short circuit in a parallel connection.

Large battery systems with high output voltage require additional insulation protection and leakage current control. Systems with high discharge current rates must be equipped with advanced current switching, routing, overcurrent, and short-circuit protection. Lithium cells can significantly differ in electrical parameters and undergo thermal and operational ageing processes in different ways during operation. Cells with significantly reduced durability must be automatically identified and eliminated. Slight discrepancies in the capacity, level of charge, or cell voltage must be reduced by passive or active balancing of the charge in all cells of the battery system. The variable voltage-current characteristics of Li-Ion cells require a four-step charging procedure, including initiation charging, activation charging, constant current (CC) charging, and constant voltage (CV) charging. Moreover, charging with a strictly defined current profile, balancing the $\mathrm{SoH}$ of the cells, and maintaining the appropriate temperature of cells improve the operational parameters and efficiency of the entire battery system. All of the presented requirements need to be perpetually controlled and managed by the BMS.

\section{Battery Management System structure}

The structure of the BMS depends on the topology of cell connections, the capacity, and the rated voltage of the battery system. BMSs can be divided into centralized and distributed structures $[27,28]$. Both types can be designed as static or reconfigurable ones [28]. The simplest BMSs are static centralized structures. A typical functional structure of a centralized BMS is shown in Figure 1.

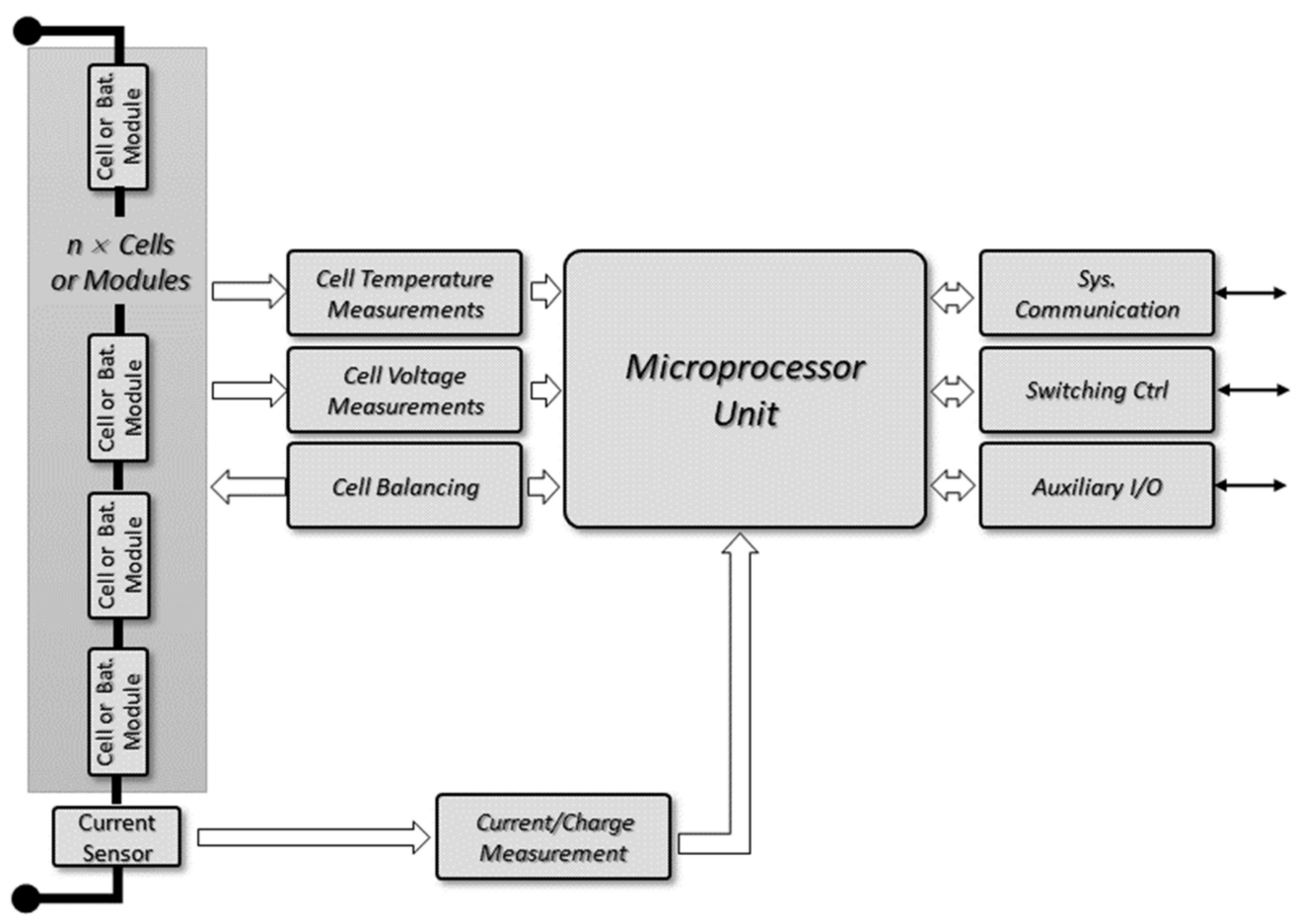

Figure 1. The structure of the static centralized Battery Management System.

The cell connection topology and technical parameters of battery systems managed by centralized BMSs result from the technical limitations of the dedicated integrated circuit (IC) of the BMS controller. Large battery systems usually built of many battery modules require BMSs configured as modular and distributed systems and ensure all the previously described functionalities for both individual cells and whole battery packs [28-30]. The number of consecutive modules connected in series is limited by either the permissible number of managed battery modules or the ICs' voltage limitations. 
ICs dedicated to the distributed BMS systems are usually equipped with various wire interfaces for inter-module digital communication. The communication interfaces use the CAN, RS485, RS422, I2C, SPI, ISOSPI, or SMBUS standards. The logic communication connections of the master controller with the slave units are typically made as wire connections in the "daisy chain", star, bus, or hybrid topology. The most significant disadvantage of such connection systems is the voltage difference between the battery modules, which requires inductive galvanic separators. Distributed BMS systems with high voltage rates combine up to 16 cells connected in series into one battery module, being logically a slave unit (SU). The modules, in turn, are electrically connected in series to obtain the required voltage of the battery system. They communicate with the master controller as SUs according to the applied BMS topology [30]. To obtain the rated output voltage of $1000 \mathrm{~V}$ in the battery system, 16 SUs of 16 cells have to be connected. Communication of all SUs with the BMS master controller (BMC) requires approximately 64 physical connections for the simplest configuration, and the same number of galvanic separators is needed. Several prototype solutions of distributed BMSs using wireless (radio) connections have been presented in the last few years [31-34]. The principle of inter-module wireless communication is the same as for systems with wired communication (Figure 2) and ensures the logical connection of the master BMC with all SUs.

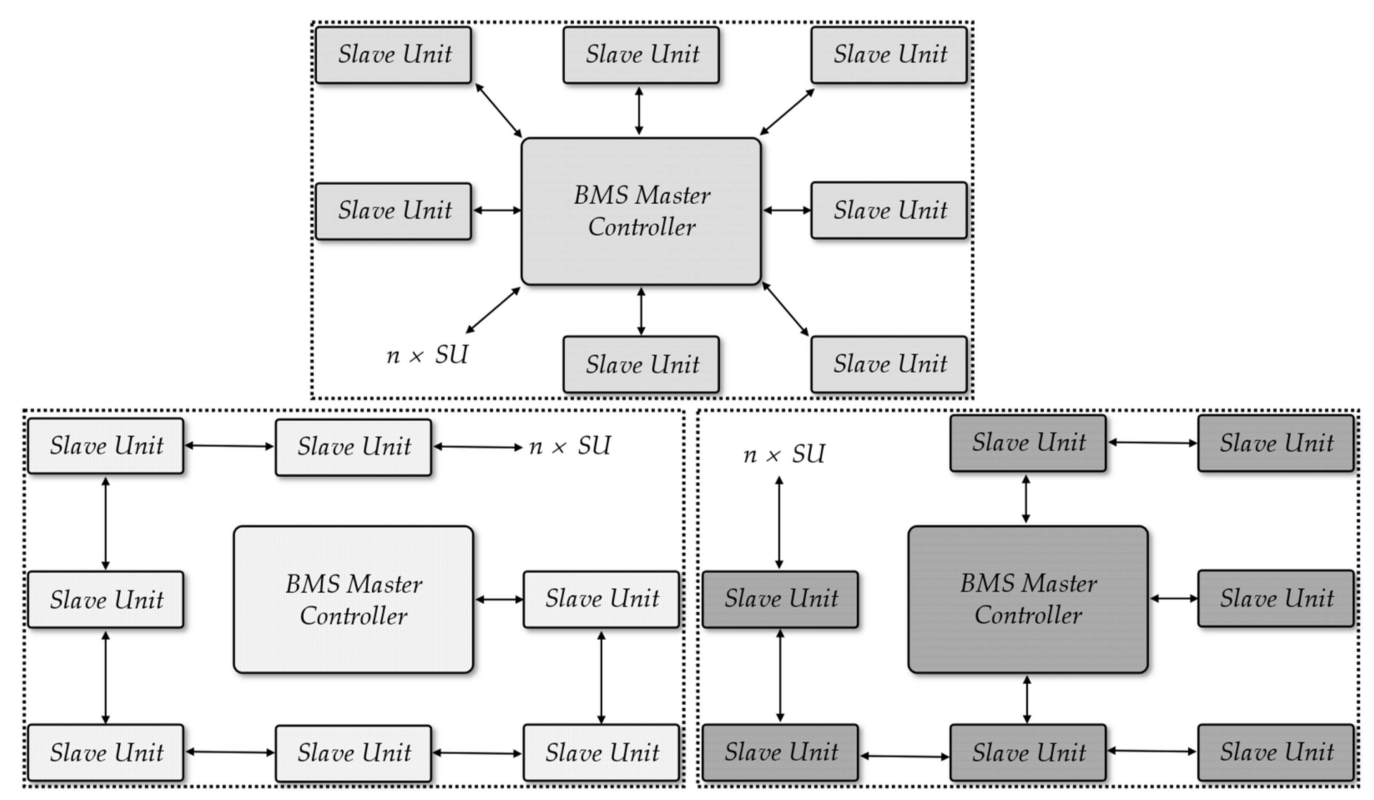

Figure 2. Exemplary structures of the distributed modular Battery Management Systems.

Most industrial systems use radio transceivers operating in the unlicensed ISM (Industrial, Scientific, Medical) frequency bands: $6.765-6.795 \mathrm{MHz}, 13.553-13.567 \mathrm{MHz}, 26.957-27.283 \mathrm{MHz}$, 40.66-40.70 MHz, 433.05-434.79 MHz, 868.00-870.00 MHz, 2.400-2.483 GHz, 5.572-5.875 GHz, 24.00-24.25 GHz, 61.00-61.50 GHz, 122.00-123.00 GHz and 244.00-246.00 GHz [35]. The most commonly used controllers are the commercial ones with RFID, NFC, Bluetooth, ZigBee, WirelessHart or WiFi communication protocols operating in the ISM bands. The ZigBee, Bluetooth or WiFi communication interfaces are most suitable for low-range wireless network sensors (WSN) applications [35]. The Analog Devices company also developed another dedicated solution called the SmartMesh IP 802.15.4e SoC wireless communication system operating in a $2.4 \mathrm{GHz}$ band. It is a solution with the most outstanding application potential for battery systems due to the functionality and the unit price of the RF transceivers. Another customized communication solution is the WiBaAN system (Wireless Battery Area Network), strictly dedicated to large battery systems [31]. The WiBaAN approach is a good reference point for other wireless communication systems developed in battery systems [31,32,36]. 


\section{Modular Battery Management System and Its Operation}

The presented approach to battery management is based on the concept of a battery system composed of a number of scalable battery modules made of Li-Ion cells and connected in series. The rated capacity of the system is thus limited by the capacity of a single battery module, while its output voltage is defined by the number of modules installed in the system and their rated voltage. Each of the battery modules is controlled directly by its SU. Each of the SUs communicates with the BMC via the wireless system to ensure better scalability and reconfiguration of the whole battery system. The developed concept of the Modular Battery Management System (MBMS) relies on two types of modules, BMC and SU(s), operating in a wireless network of a star topology (Figure 3).

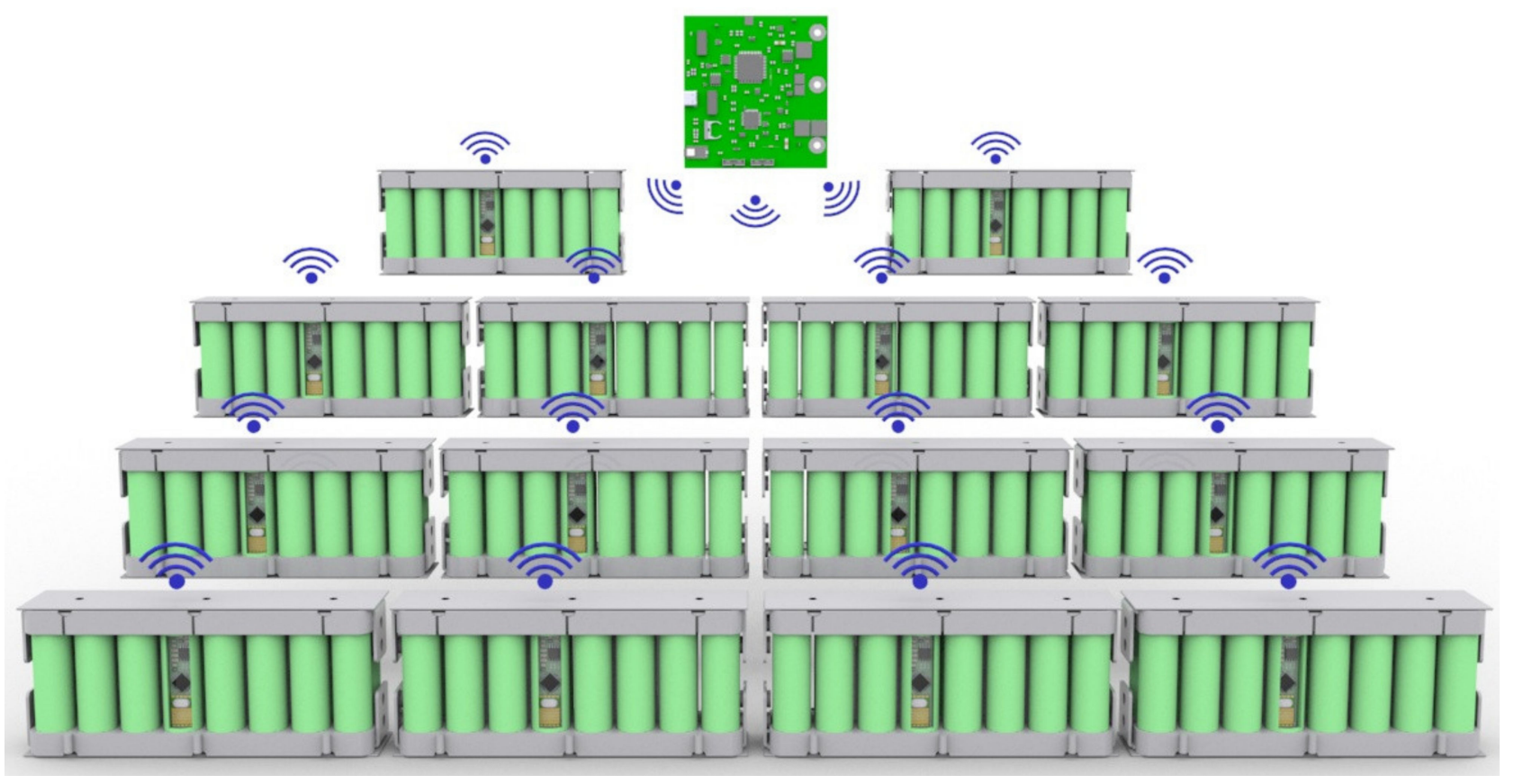

Figure 3. Concept of Modular Battery Management System with wireless communication.

The BMC unit (Figure 4) is responsible both for SoC and $\mathrm{SoH}$ control of the entire $n \cdot(1 \mathrm{~S} m \mathrm{P})$ battery system and for monitoring the status of $n$ modules in the $1 \mathrm{~S} \cdot \mathrm{mP}$ configuration managed by slave units. Based on the data sent by the SU (module voltage, temperature, auxiliary service states of the modules), the BMC estimates the current SoC and $\mathrm{SoH}$. Depending on the SoC and $\mathrm{SoH}$ parameters, the BMC initiates various operating modes and configurations, such as: balancing the modules, disconnecting the battery module, or switching the battery system to the service mode. Each SU (Figure 5) must be equipped with an Analog to Digital Converter (ADC), temperature sensor, Radio Frequency (RF) transceiver, switching, and peripheral circuits to ensure the above-described functionality of MBMS. No wonder that the battery management system consumes a certain amount of accumulated energy for its own needs and thus reduces the effective capacity and time interval between successive charges to maintain the acceptable DoD and ensure an uninterrupted power supply to the MBMS. High voltage battery systems with many units have very demanding power requirements to supply all SUs and BMC. Since every battery module operates as a power source for the MBMS, especially for the built-in SU, the critical issue is to prevent the battery system from fast self-discharging. Therefore, the authors paid special attention to the development of the low-power communication protocol along with the dedicated low-power BMC and SU devices, which would significantly reduce the power consumption of the MBMS. 


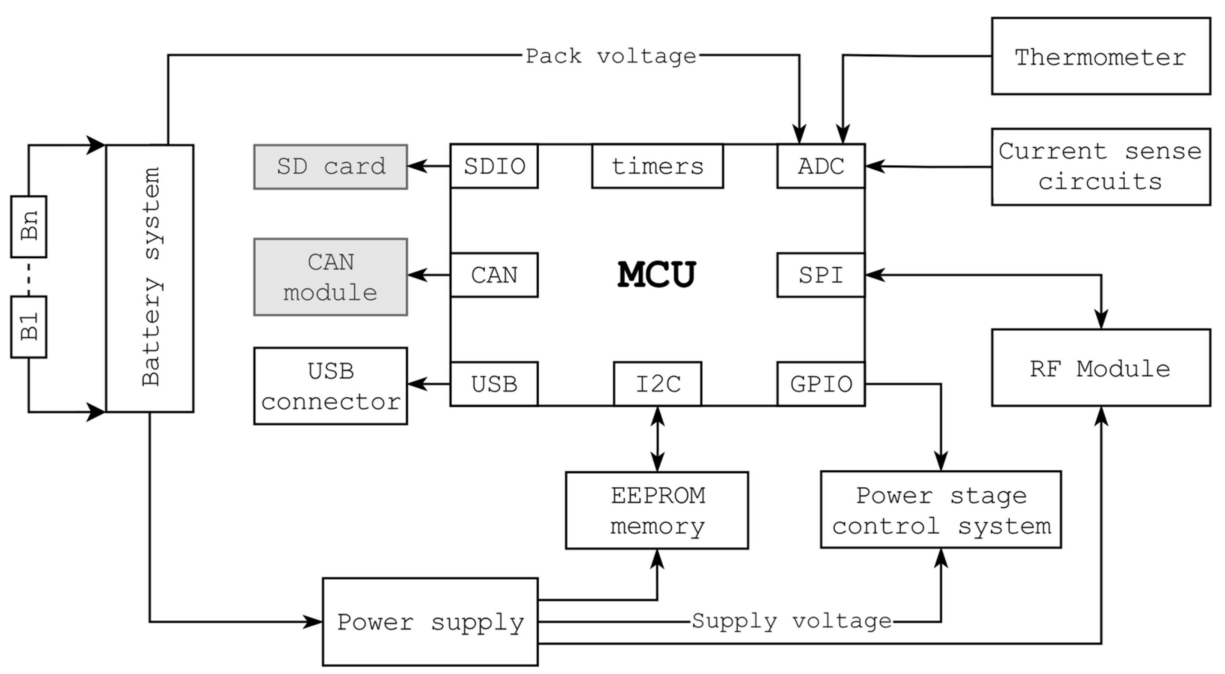

Figure 4. Generic diagram of the BMS Master Controller.

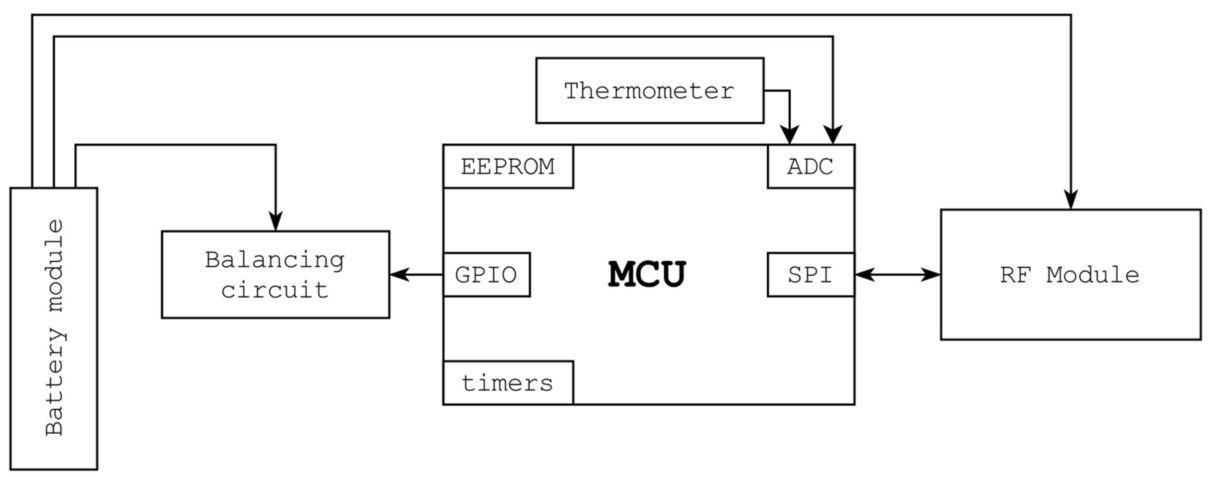

Figure 5. Generic diagram of the slave unit.

The principle of operation of the presented MBMS is based on bidirectional synchronous communication between SUs and BMC, which provides all the necessary functionalities of a typical BMS while allowing each SU to enter the Power-Down mode for the precisely specified period of time. All SUs in the system have their unique IDs but the same priority and functionality. The SUs wake up synchronously and are responsible for initializing the communication with the BMC within the defined time slots. After transmission, the SU goes into the Power-Down mode with the radio transceiver turned off. The order of messages, synchronously broadcast by the consecutive SUs, and the communication time slots are defined and synchronized by the BMC. The timing diagram of the synchronization queue is shown in Figure 6. 


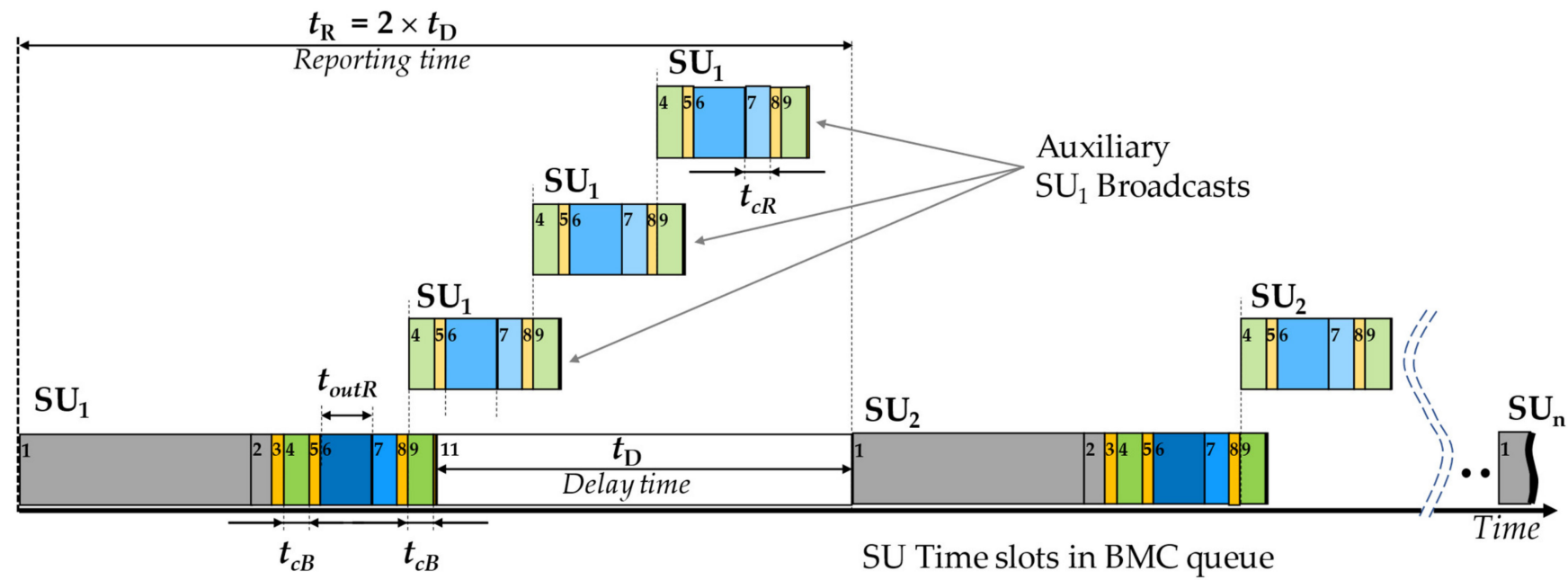

Figure 6. The timing diagram of the bidirectional synchronous communication protocol between SU and BMC (detailed description of symbols in the text of Sections 5 and 6).

The order of synchronously established RF connections causes that only one SU communicates with the BMC at a given time. All other SUs have their RF transceivers turned off and remain in the Power-Down mode until their system watchdog timer generates a wakeup interrupt after a strictly defined time interval $(n-1) \cdot t_{\mathrm{R}}$ settled and synchronized by the BMC. Longer intervals, although they might be used to reduce the power consumption even further, are not recommended since the reduced frequency of data updates in the BMC may adversely affect the safety of the battery system. The polling frequency can be decreased only in idle states of the battery system. The communication algorithm does not require that the $\mathrm{SU}$ is permanently in the listening mode. Therefore, the RF transceiver can be turned off, and the SU works most of the time in the Power-Down mode. The developed MBMS allows for a significant increase in energy efficiency thanks to the low-power electronic components used in the SU and BMC design, optimized communication, and the unique MBMS operation algorithms. A detailed description of communication algorithm and energy efficiency studies are presented in the following sections.

\section{MBMS Algorithms}

The MBMS performs all necessary operations to monitor SoC and SoH parameters. It is also responsible for controlling the power stage of the battery system during charging and exploitation. The system output state is checked, and the $\mathrm{SoC}$ is determined based on the V-I curves of the cells, the instantaneous charging/discharging current, each module voltages, and system output voltage measurements. The $\mathrm{SoH}$ is determined based on the temperature of the modules, the number of previous charging/discharging cycles, C-rate profiles, and technical data of the cells. BMC aggregates the data transmitted by all SUs and provides real-time access to the operational parameters of the battery system. The MBMS operations are performed in three primary processes: assembling, reporting, and management.

Pairing the battery modules with the BMC is part of the battery system manufacturing process and is performed once. During this process, the BMC configures the battery system topology, identifies all battery modules, and creates a communication queue with all SUs installed in the battery modules (Figure 7). 


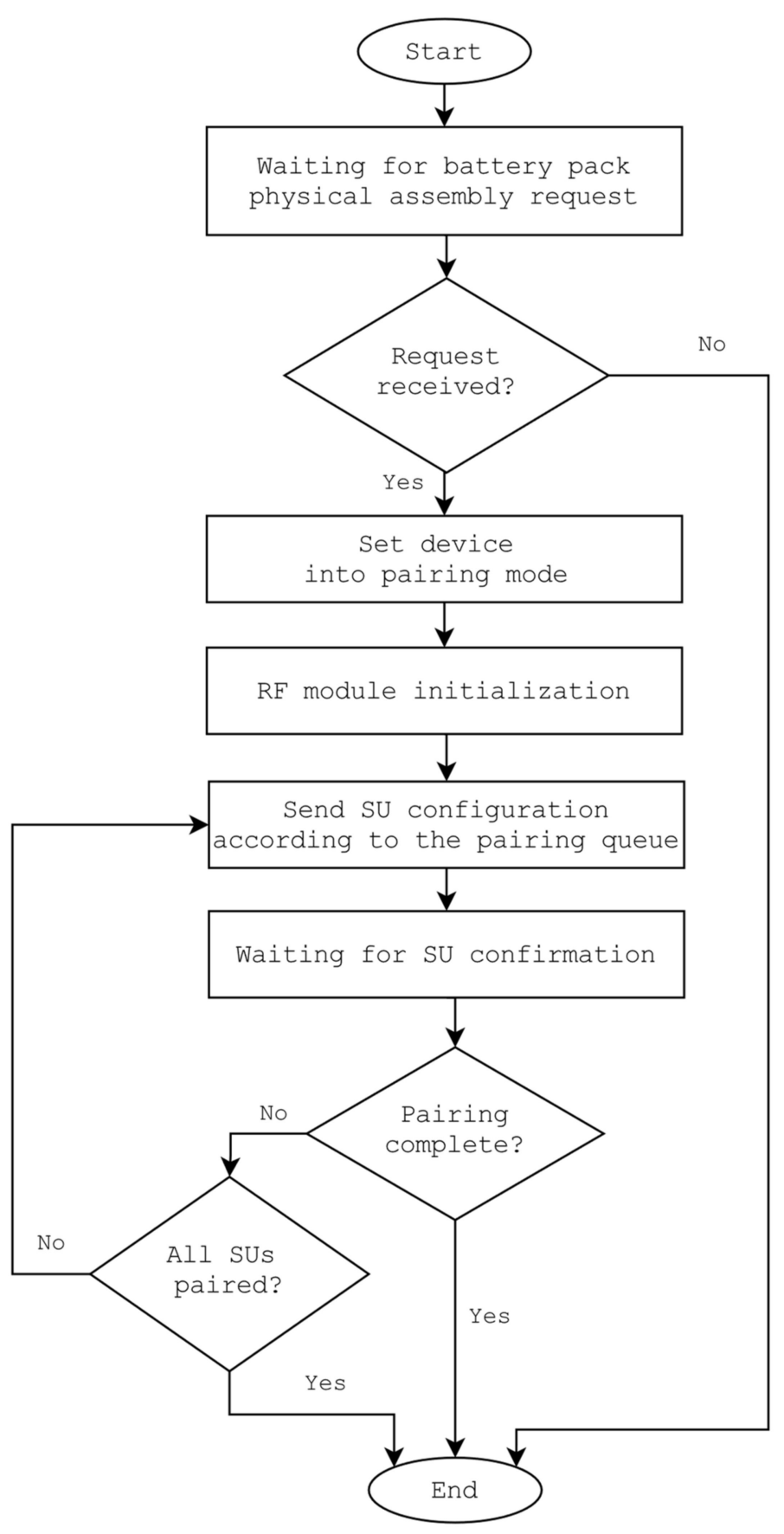

Figure 7. Algorithm of pairing Slave Units with the BMC into a modular battery system.

In order to pair devices, the BMC initiates the module pairing mode using external software. The BMC listens for messages broadcast by consecutive SUs, places them in the queue, and determines the time interval of the subsequent response for each of them. Each SU has a unique ID number that is assigned to a physical battery module. Validation and completion of the assembly process are done manually by the builder of the battery system.

After the assembly process is completed, the BMC goes into the normal operation mode and executes the battery management process. The management process implements two simultaneous threads: maintaining communication with all SUs and managing the battery system. The algorithm of this process is illustrated in Figure 8. 


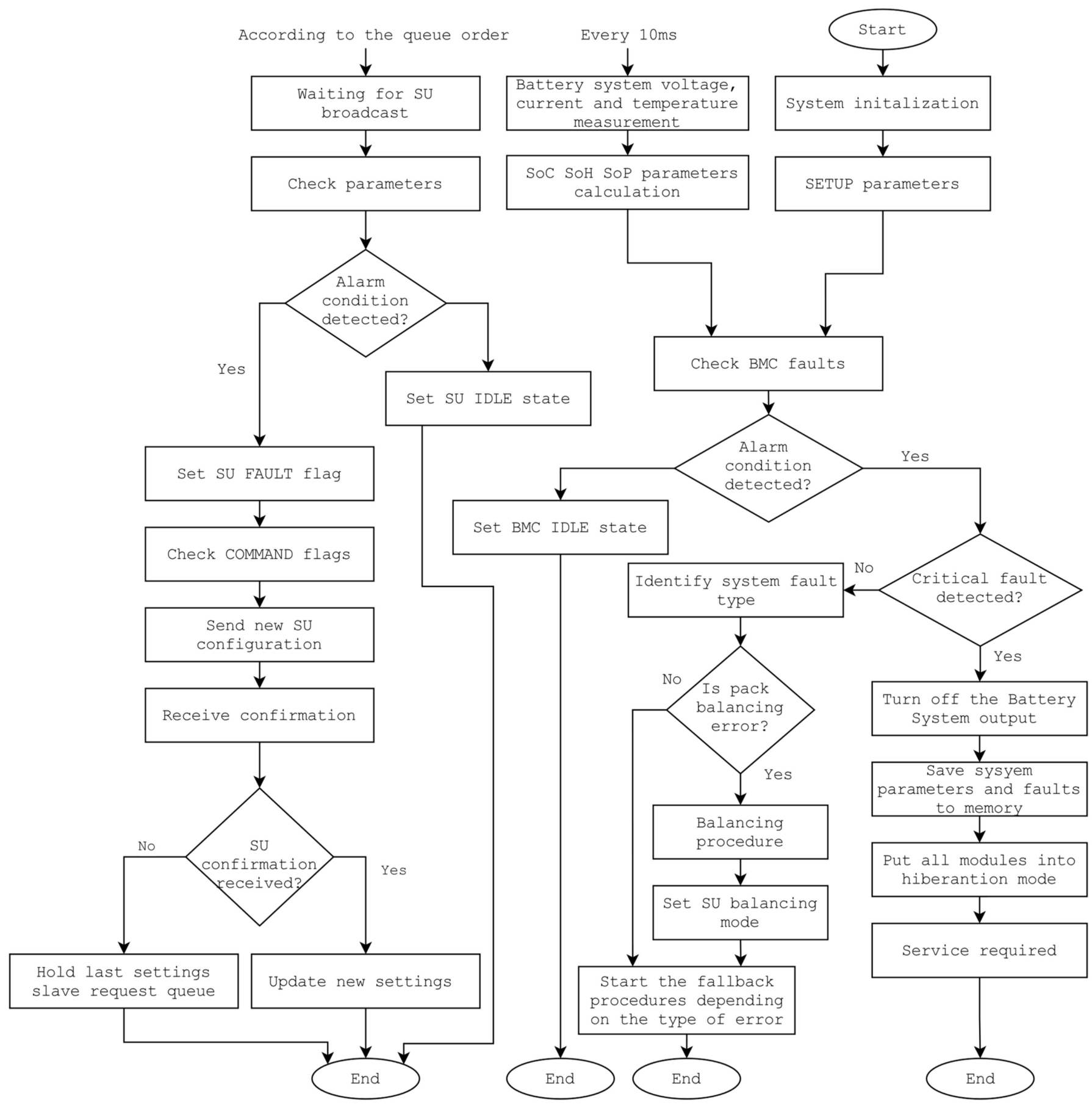

Figure 8. Algorithm illustrating the management process executed by the BMC.

The BMC checks in the ongoing management process that the SU responds according to the prescribed schedule and analyzes the received data. The BMC is also equipped with its own voltage, current, and temperature measurement system, which collects information about the output parameters of the entire battery system needed to update the SoC and SoH parameters. The BMC analyzes collected data to detect alarm threshold limits or critical system errors. Appropriate procedures are executed if the errors are not critical (e.g., a charger disconnect, a load disconnect, start balancing, run the cooling system). A critical safety procedure is triggered when the monitored parameters are out of range. The BMC turns off unnecessary peripherals, all SUs are switched to power-down mode, and the error $\log$ is saved in the non-volatile memory. After the modules have entered the Power-Down mode, a service action is required. 
The reporting process is executed by all SUs installed in the battery system. The synchronization and queuing of this process take place in the BMC. Each SU performs the procedure at strictly defined time intervals in the given order according to the schedule shown in Figure 6. The order of establishing SU-BMC connections is essential because all SUs use the same frequency band (e.g., $868 \mathrm{MHz}$ ) for communication. To avoid communication collisions and message overlapping, only one SU may be in the message broadcasting mode at the defined time $t_{R}$. The appropriate time $t_{D}$ must elapse before reporting by another SU. To complete communication, the SU must send back an acknowledgement with a new $(n-1) \cdot t_{\mathrm{R}}$ value and trigger the Power-Down mode for $(n-1) \cdot t_{\mathrm{R}}$ time. The $\mathrm{BMC}$ receives the acknowledgement and assigns it to the queue time slot when the given SU should re-report its state again.

According to the algorithm (Figure 9), the SU monitors the current state of charge, the temperature, and the balancing status of the battery module. If either the monitored parameters have reached critical values or communication with the BMC has been lost, the SU goes into a permanent Power-Down state. Service action is required to reactivate the unit. The SU writes an appropriate status flag (BYTE 4, 'Command') in the memory, which blocks the re-initialization of the ADC and the RF transmitter, and pauses the balancing procedure. When the SU detects the absence of critical states, it enters the normal operation mode and establishes communication with the BMC. After the reporting process is completed, the SU goes into the Power-Down mode for the time interval set by the BMC. Collision-free communication with all $\mathrm{n}$ SUs installed in the system requires time $t_{\mathrm{S}}=n \cdot t_{\mathrm{R}}$ then, each SU connected to the battery system may exchange messages with the BMC once during every $t_{\mathrm{S}}$ cycle, according to the BMC-controlled schedule. The redundant time $t_{\mathrm{D}}$ can be used for additional attempts to reconnect the SU with the BMC (Figure 6). The maximum scanning frequency of a system composed of $n$ units is $f_{\mathrm{s}}=\left(n \cdot t_{\mathrm{R}}\right)^{-1}$. Scanning frequency can be adjusted by changing the time $t_{D}$ or $t_{R}$ when it is necessary. The BMC may only decrease the transmission frequency when all SoC, SoH parameters remain in the optimal range. The $t_{\mathrm{CB}}$ and $t_{\mathrm{CR}}$ times have a dominant influence on the $f_{\mathrm{s}}$ because they determine how long the radio communication channel is occupied. The $t_{\mathrm{cB}}$ and $t_{\mathrm{cR}}$ time intervals depend on the wireless communication interface and the length of the data frames sent by the SU and the BMC. The layout of the frames broadcast by both units is shown in Figure 10a,b. The communication data frame sent by the SU includes new measurements of module voltage $V_{\mathrm{BM}}$ and temperature $T_{\mathrm{BM}}$, balancing status, and feedback on the value of the last time interval $(n-1) \cdot t_{\mathrm{R}}$. The acknowledgement frame transmitted by the BMC contains information about the new $(n-1) \cdot t_{\mathrm{R}}$ value and the feedback confirmation of the $V_{\mathrm{BM}}, T_{\mathrm{BM}}$, and balancing status readings obtained from the SU. 


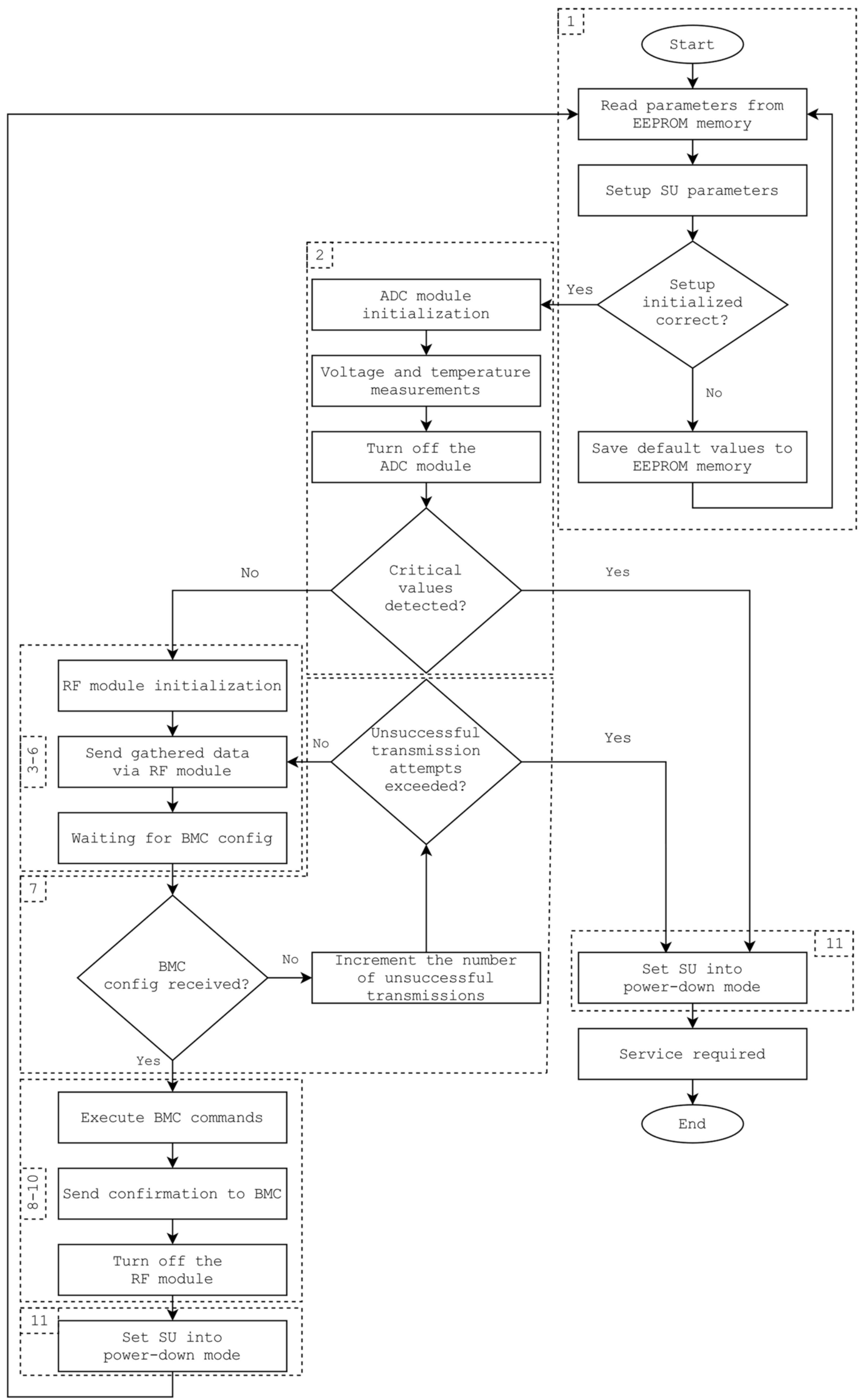

Figure 9. Algorithm illustrating the reporting process executed by all Slave Units. 


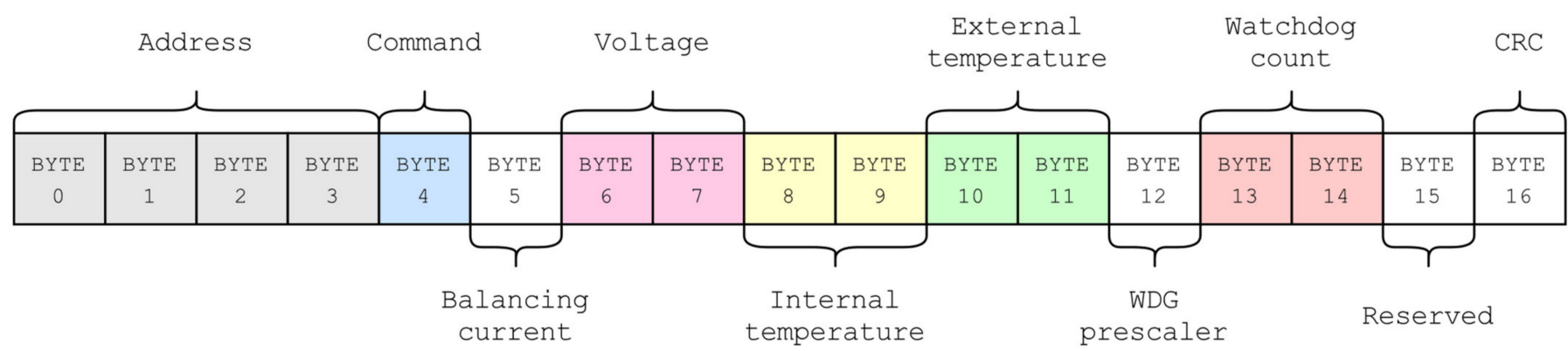

(a)

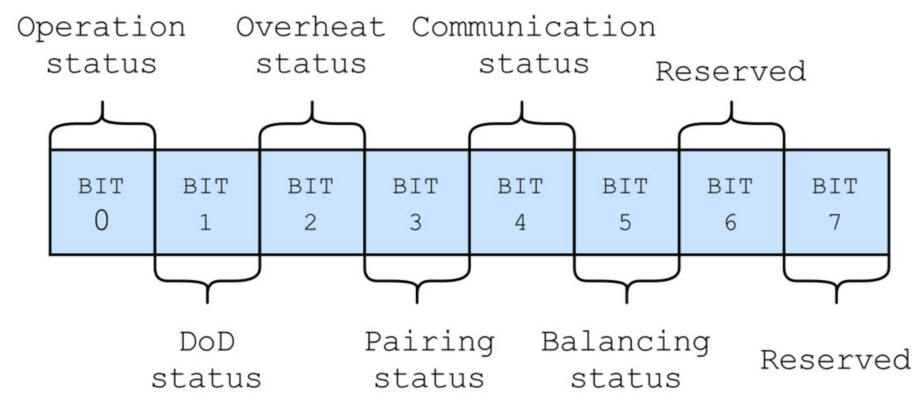

(b)

Figure 10. Communication between the MBMS modules: (a) the layout of communication frames sent by BMC and SU; (b) status flags in the 'Command' Byte (4).

In addition, a CRC checksum is continuously calculated in each communication frame. The transmission is considered correct only when the computed checksum is equal to the sent value. Otherwise, the data transfer process will be repeated. After sending information, the $\mathrm{SU}$ waits for a confirmation response from the BMC until the timeout $t_{\text {outR }}$ expires. If the acknowledgement is received, the $\mathrm{SU}$ confirms it to the BMC at the time $t_{\mathrm{cR}}$, executes the received commands, and triggers the Power-Down mode for $(n-1) \cdot t_{\mathrm{R}}$ time. If there is no appropriate confirmation from the $\mathrm{BMC}$, the $\mathrm{SU}$ tries to establish communication three times. In the case of no further responses, the SU goes into the Power-Down state and requires a service action.

\section{Evaluation of MBMS Energy Efficiency}

Evaluation of the MBMS efficiency requires identifying all periodic, anomalous, and continuous processes in the MBMS that require to be supplied from the battery system. A comparative analysis was carried out for various operating states to confirm the increased energy efficiency of the MBMS. Measurements of instantaneous supply current and energy consumption by the BMC were carried out in the normal operation mode. The SU has been tested in the following modes: establishing a connection with the BMC module, reporting in the normal operation mode, and reconnecting in a communication error state. Evaluation of the energy efficiency was carried out for components specified in Table 1, while the configuration of the MBMS hardware was consistent with Figures 4 and 5 . 
Table 1. MBMS and battery module technical specification.

\begin{tabular}{|c|c|c|c|}
\hline MBMS Units & Components & Component ID & Manufacturer \\
\hline \multirow{13}{*}{$\mathrm{BMC}$} & $\begin{array}{c}\text { MCU (32 bit ARM CPU + internal thermometer, } \\
\text { USB, SPI, I2C, ADC, GPIO, Timers) }\end{array}$ & STM32F407VET & ST Microelectronics \\
\hline & RF Transceiver $868 \mathrm{MHz}$ & SI4421 & Silicon Labs \\
\hline & CAN Transceiver (Not used in tests) & SN65HVD230 & Texas Instruments \\
\hline & Buck regulator & AOZ1282CI & Alpha \& Omega Semiconductor \\
\hline & Low dropout voltage regulator & LT1117-3.3 & Linear Technology \\
\hline & Low voltage comparator & LMV331 & ST Microelectronics \\
\hline & EEPROM Memory & $24 \mathrm{C} 256$ & Microchip \\
\hline & Power MOSFET driver & MCP1402 & Microchip \\
\hline & SD Card (Not used in tests) & SDCS2/32 GB & Kingston \\
\hline & Photocoupler & LTV-357T & Liteon \\
\hline & Current shunt monitor & INA199A3 & Texas Instruments \\
\hline & DC-DC Converter & MP9488GS-Z & Monolithic Power Systems \\
\hline & Digital Potentiometer & МCP4531 & Microchip \\
\hline \multirow{2}{*}{$\mathrm{SU}$} & $\begin{array}{c}\text { MCU (8 bit CPU, ADC, SPI, Timers, thermometer, } \\
\text { GPIO, EEPROM) }\end{array}$ & ATMega328P & Microchip \\
\hline & RF Transceiver $868 \mathrm{MHz}$ & SI4421 & Silicon Labs \\
\hline Cell & Li-Ion cell 18650-type & US18650VTC6 & Murata \\
\hline Battery module & 1S15P $3.7 \mathrm{~V}, 45 \mathrm{Ah}$ & ECO-BPack & BTO Ltd. \\
\hline
\end{tabular}

The 24-bit Dynamic Signal Analyzer NI PCI 4462 and calibrated shunt resistors $0.1 \Omega$ and $1.0 \Omega$ were used to investigate current profiles and to measure the instantaneous supply current. The average current consumed by the BMC at $12.0 \mathrm{VDC}$ is $23.7 \mathrm{~mA}$. The BMC supply current waveform has no variable component, and the instantaneous power is approximately constant. The RF transceiver has a dominant influence on the energy consumption because it is constantly waiting for communication with SUs. All BMC components that contribute to the total power consumption are summarized in Table 2.

Table 2. Rated power requirements of the BMC components in normal operation mode.

\begin{tabular}{|c|c|c|c|c|c|c|c|}
\hline BMC Module & Component & $\mathrm{I}_{\mathrm{AVG}}(\mathrm{mA})$ & $\mathbf{P}_{\text {MAX }}(\mathrm{mW})$ & $\mathrm{E}(\mathrm{mJ})$ & VSS (V) & $t(s)$ & Description \\
\hline MCU & STM32F407VET & 44.00 & 204.60 & 1506.30 & 3.3 & 10.374 & MCU \\
\hline Radio & SI 4421 & 12.00 & 46.20 & 410.81 & 3.3 & 10.374 & RF \\
\hline CAN & SN65HVD230 & 0.37 & 1.98 & 12.67 & 3.3 & 10.374 & CAN \\
\hline \multirow[t]{2}{*}{ EEPROM } & $24 \mathrm{C} 256$ & 0.05 & 0.25 & 2.59 & 5.0 & 10.374 & EEPROM \\
\hline & MP9488GS-Z & 0.01 & 10.00 & 41.50 & 400.0 & 10.374 & DC-DC Converter \\
\hline \multirow[t]{2}{*}{ Power Supply } & LT1117-3.3 & 5.00 & 50.00 & 259.35 & 5.0 & 10.374 & DC-DC Converter \\
\hline & AOZ1282CI & 1.00 & 18.00 & 155.61 & 15.0 & 10.374 & DC-DC Converter \\
\hline \multirow{3}{*}{$\begin{array}{l}\text { Current sense } \\
\text { circuits }\end{array}$} & 2x INA199A3 & 0.13 & 0.66 & 4.45 & 3.3 & 10.374 & OPAMP shunt \\
\hline & MCP4531 & 0.003 & 0.017 & 0.09 & 3.3 & 10.374 & Digital potentiometer \\
\hline & LMV331 & 0.02 & 0.33 & 0.68 & 3.3 & 10.374 & Overcurrent comparator \\
\hline \multirow{5}{*}{$\begin{array}{l}\text { Power stage } \\
\text { control system }\end{array}$} & MCP1402 & 0.85 & 16.50 & 132.27 & 15.0 & 10.374 & HS MOSFET Driver \\
\hline & LTV-357T & 1.00 & 75. 00 & 155.61 & 15.0 & 10.374 & Optocoupler \\
\hline & LED diode & 5.00 & 33. 00 & 171.17 & 3.3 & 10.374 & LED \\
\hline & \multicolumn{2}{|c|}{ Total Estimated Energy } & & 2853.10 & & & \\
\hline & \multicolumn{2}{|c|}{ Total Measured Energy } & & 2951.11 & & & \\
\hline
\end{tabular}

The instantaneous supply current depends on the operating mode and the process executed in a given SU. While the battery system is being assembled, every SU is paired with the BMC, configured, and begins cyclic reporting (Figure 7). A typical instantaneous current profile for this process is shown in Figure 11. The increased supply current of $12.7 \mathrm{~mA}$ after the first activation of the SU occurs due to its waiting in the receiving mode for establishing communication with the BMC. A further short-term increase to $14.2 \mathrm{~mA}$ means that the SU has entered the transmitting mode and communicates with the BMC. The plunge of current to the value of $18 \mu \mathrm{A}$ after successful pairing means that the SU has entered the Power-Down mode. The successive periodic spikes in the graph show the SU activity during the repeated reporting process. 


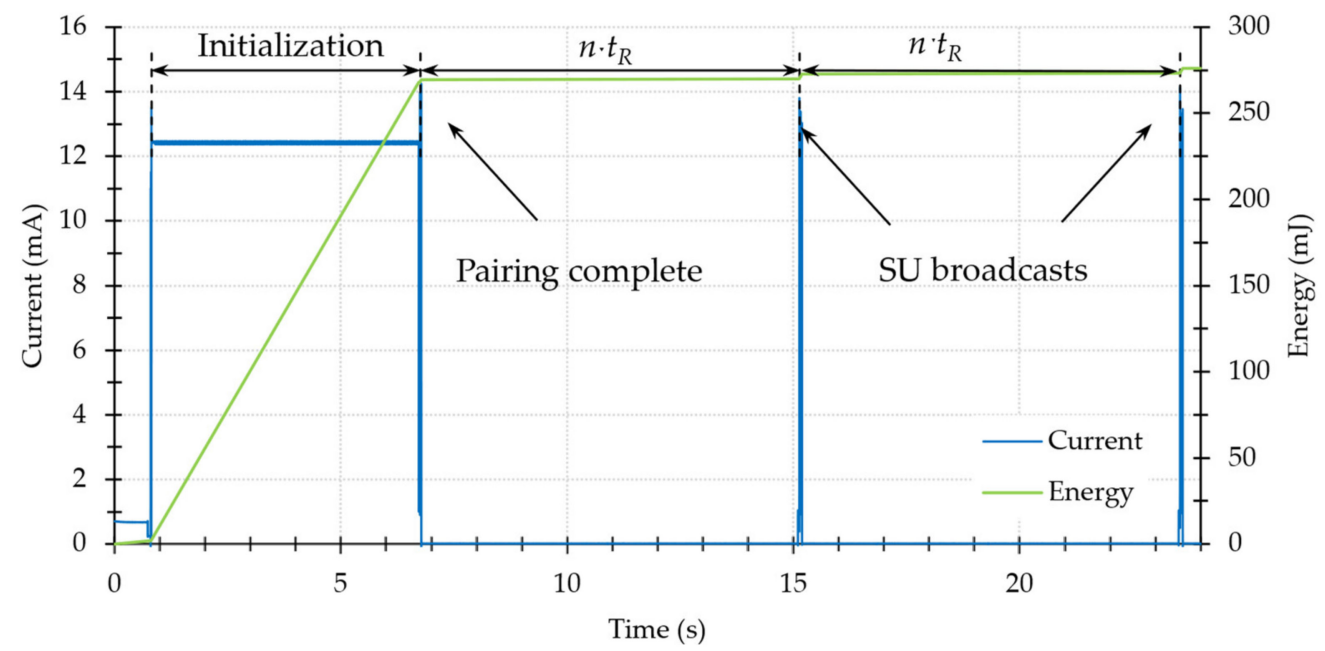

Figure 11. Typical instantaneous supply current and energy transfer to the SU prior to and during the initial connection with the BMC and the sequential reporting.

This process is repeated many times by all SUs installed in the battery system and has a crucial influence on the MBMS current consumption in normal operation mode. A detailed profile of the supply current of the reporting SU is shown in Figure 12.

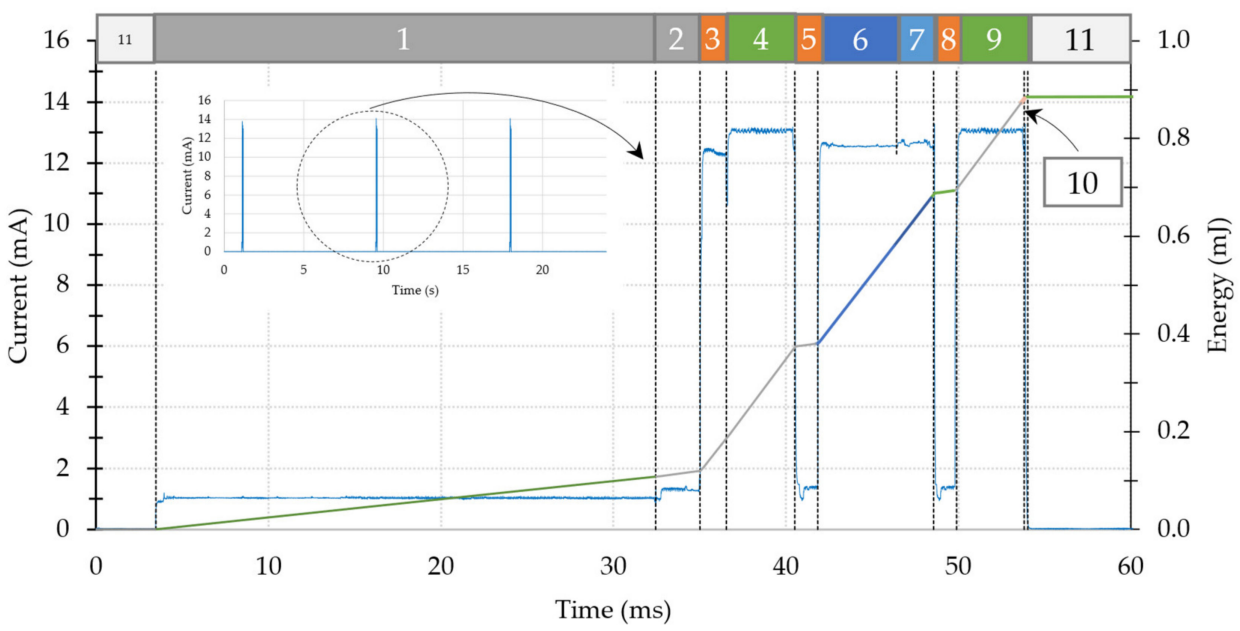

Figure 12. Typical instantaneous supply current and energy transfer for the reporting SU in the normal operating mode.

The waveform of the instantaneous current while reporting is closely correlated with stages of the reporting process. Time intervals marked in Figure 12 with colors and numbers refer to the sequential operations specified in the algorithm shown in Figure 9 and characterized in Table 3. Initialization of the SU and reading the configuration data (step 1) takes more than half of the reporting time $t_{R}$. Built-in features and architecture of the microcontroller impact the magnitude of current and time duration of this stage. Step (2) involving initialization of the ADC, taking measurements of the voltage $V_{\mathrm{BM}}$ and the temperature $T_{\mathrm{BM}}$ of the module, data handling, and turning off the ADC is roughly short and has a small contribution to the total current consumption during reporting. The steps labeled 3, 4, 6, 7, and 9 are responsible for the initialization and operation of the RF module. During these operations, the current consumption reaches a value of $12.9 \mathrm{~mA}$. The time of initialization (3) and transmission (4 and 9) is fixed. While waiting for an acknowledgement from the BMC (6), the SU may remain in the receive mode for $t_{\text {outR }}$ and then receive the data for the time $t_{\mathrm{cR}}$. The system reconfiguration is carried out in steps 5 and 8 . The time duration of this operation does not exceed $1.33 \mathrm{~ms}$, and the supply current 
drops to the value of $3 \mathrm{~mA}$. In the last step (10), the RF module is turned off, the data are stored in the SU memory, and the watchdog timer is set. The execution time is negligibly short, but the maximum current consumption is the same as when the $\mathrm{SU}$ is transmitting or receiving. After the reporting has been completed, the SU goes into the Power-Down mode (11) for the time $(n-1) \cdot t_{\mathrm{R}}$ and reduces the supply current to $18 \mu \mathrm{A}$.

Table 3. Power requirements of the SU in normal operation mode.

\begin{tabular}{|c|c|c|c|c|c|c|c|}
\hline Step No. & Event Type & $\mathrm{I}_{\mathrm{AVG}}(\mathrm{mA})$ & $I_{\text {MAX }}(\mathrm{mA})$ & $P_{\text {MAX }}(\mathrm{mW})$ & $E(\mu J)$ & VSS (V) & $\mathrm{t}(\mathrm{ms})$ \\
\hline 1 & EEPROM and MCU initialization & 1.02 & 1.20 & 4.46 & 107.01 & 3.62 & 28.98 \\
\hline 2 & ADC initialization and measurements & 1.27 & 1.43 & 5.32 & 11.82 & 3.62 & 2.57 \\
\hline 3 & RF initialization & 11.45 & 12.49 & 46.48 & 63.42 & 3.62 & 1.53 \\
\hline 4 & RF communication & 12.98 & 13.17 & 49.00 & 186.54 & 3.62 & 3.97 \\
\hline 5 & Switching RF mode & 2.52 & 12.83 & 47.71 & 12.13 & 3.62 & 1.33 \\
\hline 6 & Waiting for BMC acknowledgment & 12.17 & 12.69 & 47.19 & 201.33 & 3.62 & 4.57 \\
\hline 7 & Receiving data from BMC & 12.65 & 12.78 & 47.55 & 98.45 & 3.62 & 2.15 \\
\hline 8 & Switching RF mode & 3.14 & 13.17 & 49.01 & 15.12 & 3.62 & 1.33 \\
\hline 9 & Sending acknowledgment to BMC & 12.69 & 13.16 & 48.97 & 180.08 & 3.62 & 3.92 \\
\hline 10 & $\begin{array}{l}\text { Turning off the RF module and BMC } \\
\text { command execution }\end{array}$ & 12.79 & 13.17 & 49.00 & 9.72 & 3.62 & 0.21 \\
\hline 11 & Power-Down mode & 0.02 & 0.06 & 0.22 & 3.74 & 3.62 & 51.60 \\
\hline
\end{tabular}

In the normal operation mode, one $\mathrm{SU}$ is activated every $t_{\mathrm{R}}$ time and does not require waiting for any events related to the synchronization with the BCM. Upon completing the reporting process, the SU immediately goes into the Power-Down mode to minimize power consumption. SUs enter the communication error mode when errors occur during either reporting (Figure 13) or adding the SU to the system (Figure 14). The error mode is also triggered when either the $\mathrm{SU}$ has not received an acknowledgement from the BMC before the $t_{\text {outR }}$ time expires or errors occurred in the received acknowledgement. In the error mode, the $\mathrm{SU}$ terminates the current reporting process after the step 8 and once again enters the step 4 (Figures 6 and 9), trying to establish the correct communication with the $\mathrm{BMC}$. If it receives an acknowledgement from the BMC and completes reporting within three attempts, it enters the normal operation mode with the parameters received in the last successful data exchange. Otherwise, if such a triple attempt is unsuccessful, the SU enters the Power-Down mode and requires service.

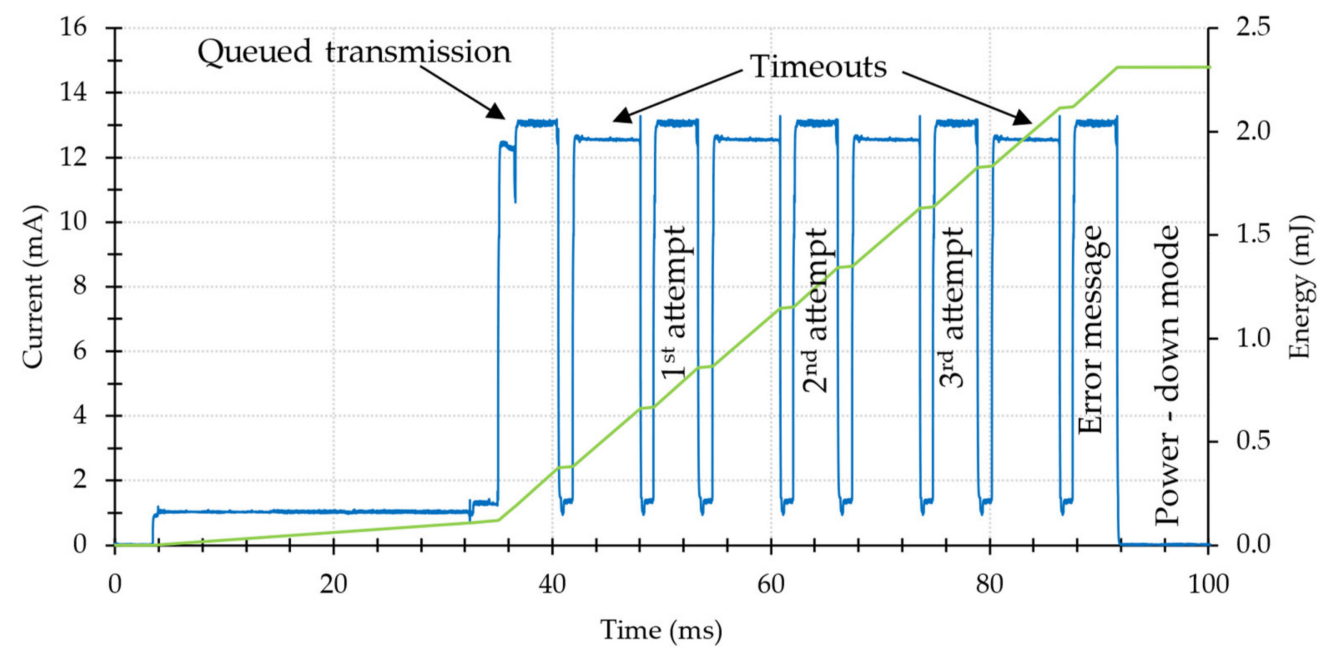

Figure 13. Instantaneous supply current and energy transfer for the SU operating in the communication error mode triggered during reporting. 


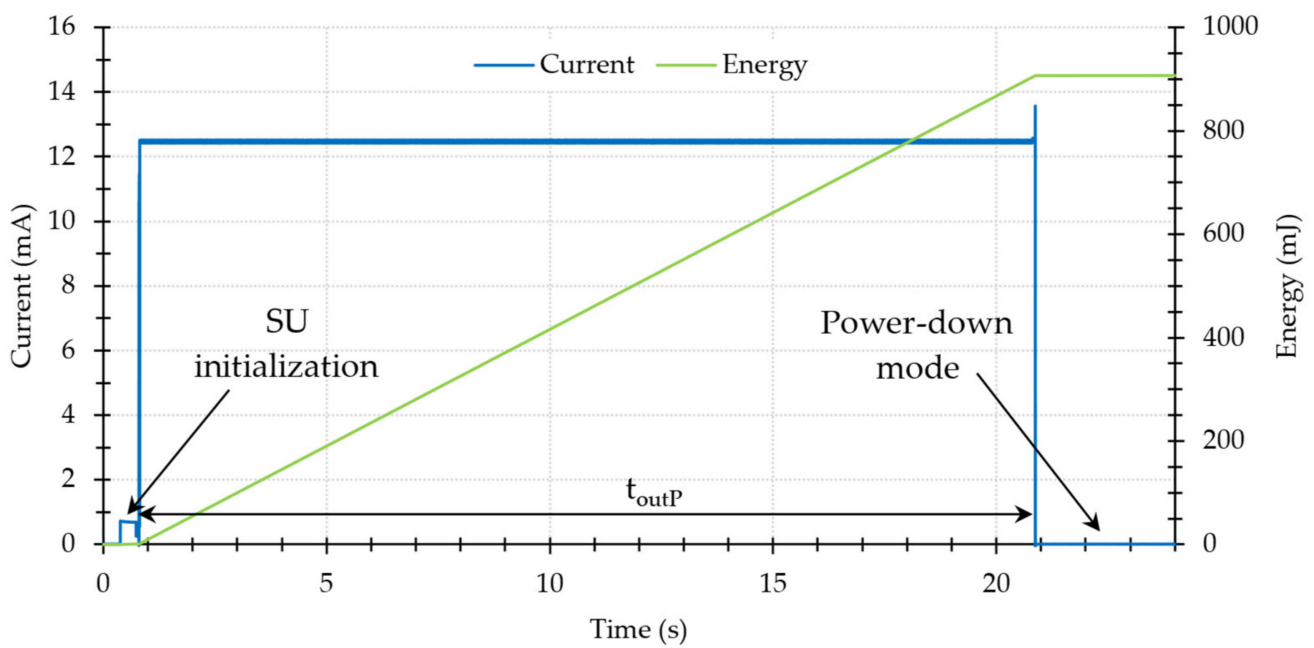

Figure 14. Instantaneous supply current and energy transfer for the SU detecting the communication error during the assembling of a system.

Handling a communication error during the assembly process is different than dealing with the communication error during reporting. If pairing has not occurred for more than $t_{\text {outP }}>n \cdot t_{R}$, the SU goes into the Power-Down mode. Resuming its pairing with the BMC can only be done in the service mode.

Figure 14 manifests the communication error in the SU as the increased current consumption of $12.65 \mathrm{~mA}$, resulting from the activity of the RF transceiver in the receive mode for the time $t_{\text {outP. }}$. Then, the SU goes into the power-down mode after a failed pairing attempt and reduces the power consumption to $18 \mathrm{uA}$. Figures 15 and 16, and Table 4 present the components of the MBMS power budget in all analyzed operating modes.

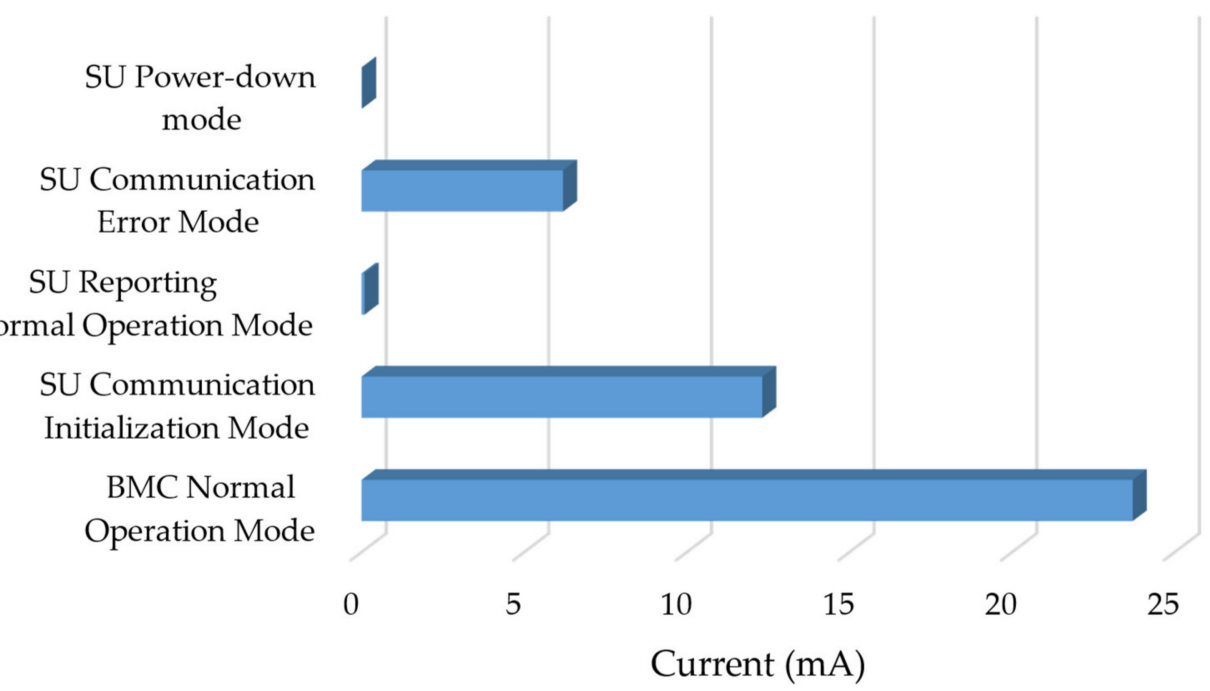

Figure 15. Comparative data of the MBMS supply current in all analyzed operating modes. 


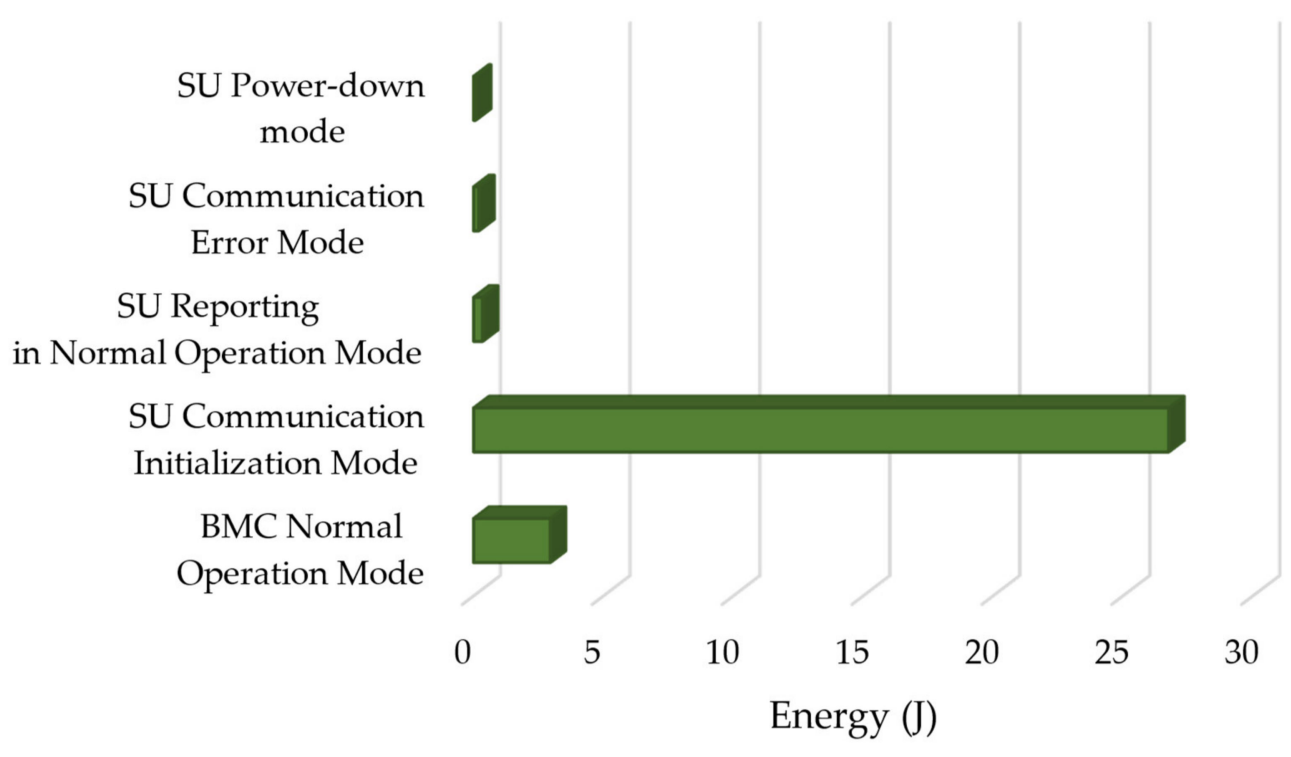

Figure 16. Energy consumption of the MBMS in all analyzed operating modes.

Table 4. Power requirements comparison of the MBMS components.

\begin{tabular}{ccccccc}
\hline BMC/SU Mode & $\mathbf{I}_{\text {AVG }}(\mathbf{m A})$ & $\mathbf{I}_{\text {MAX }}(\mathbf{m A})$ & $\mathbf{P}_{\text {MAX }}(\mathbf{m W})$ & $\mathbf{E}(\mathbf{m J})$ & VSS $(\mathbf{V})$ & $\mathbf{t}(\mathbf{s})$ \\
\hline BMC Normal Operation Mode & 23.706 & 25.162 & 301.95 & 2951.1 & 12.00 & 10.374 \\
SU Communication Initialization Mode & 12.318 & 14.145 & 169.74 & 267.5 & 3.62 & 6.000 \\
SU Reporting in Normal Operation Mode & 0.091 & 14.384 & 172.61 & 3.4 & 3.62 & 10.374 \\
SU Communication Error Mode & 6.195 & 13.174 & 158.10 & 2.0 & 3.62 & 0.088 \\
SU Power-Down mode & 0.018 & 0.027 & 0.32 & 0.7 & 3.62 & 10.374 \\
\hline
\end{tabular}

Assuming that the tested battery system consists of one hundred battery modules 100S1P (3.7 V, 45 Ah per module), one can calculate that the system can store the energy of $59.94 \mathrm{MJ}$. Assuming further that the MBMS works uninterruptedly under rated conditions, the energy needed to complete one BMC communication cycle with one hundred SUs is $3.291 \mathrm{~J}$, according to the presented measurements (Table 4). The stored energy is enough to perform $18.2 \times 10^{6}$ communication cycles. Each reporting cycle lasts no less than $10.374 \mathrm{~s}$. Thus, if no other losses are taken into account, the energy accumulated in the system is enough to supply the MBMS for six years before it reaches $100 \%$ DoD. The energy consumption of the considered MBMS is comparable to the inherent processes that take place in modern lithium cells. Comparing the annual energy consumption of the MBMS, being at the level of $16 \%$ of the battery system capacitance, one can see that this amount is less than the energy dissipated due to the self-discharge of lithium batteries at room temperature, which is about $20 \%$ per year [6].

Table 5 shows the energy consumption needed to perform a single data transmission from SU to BMC (Figure 12, Table 2). The obtained results were compared with equivalent mesh networks, which have similar communication rules to the presented MBMS. A single low-power node (LPN) containing a dedicated system on chip LTC5800-LMT needs approximately $337 \mu \mathrm{J}$ to communicate with the adjacent node. Assuming the average connection path consists of two additional descendant nodes, the estimated energy needed for communicating with the master node is about $1.0 \mathrm{~mJ}$ [37]. Other studies [38,39] present the energy consumption evaluation of low-power nodes operating in the Bluetooth mesh networks. Assuming the optimized Receive window time of $49.04 \mathrm{~ms}$ [38], the estimated energy consumption per transmission is $2.4 \mathrm{~mJ}$ (nRF52840) [38] and $2.1 \mathrm{~mJ}$ (nRF51422) [39], respectively. These values only take into account communication between adjacent nodes. This solution is the simplest scenario for mesh networks because it assumes that intermediate communication nodes are not involved in transmission to the master. Thus, the 
comparison shows that BLE LPNs that could be adapted to the MBMS have more than two times worse energy efficiency, and LPN with the dedicated system has similar power requirements to the SU.

Table 5. Power requirements comparison of similar network nodes.

\begin{tabular}{|c|c|c|c|c|}
\hline SU/Counterpart & $E(m J)$ & VSS (V) & $\mathrm{t}(\mathrm{ms})$ & Remarks \\
\hline SU Reporting in Normal Operation Mode & 889.4 & 3.62 & 50.56 & Single reporting (Table 3) \\
\hline LTC5800-LTM Low-Power Node & 336.6 & 3.60 & 22.0 & $\begin{array}{l}\text { Single transmission } \mathrm{TX}+\mathrm{RX}+ \\
\text { Doze (atomic operations) }[36]\end{array}$ \\
\hline nRF52840 Low-Power Node & 2412.6 & 3.00 & 95.86 & $\begin{array}{l}\text { Single transmission RX }+\mathrm{TX}+ \\
\text { other actions in BTLBT mode [37] }\end{array}$ \\
\hline nRF51422 Low-Power Node & 2118.4 & 3.00 & 95.86 & $\begin{array}{c}\text { Single transmission } \\
\text { 3xAdvertising + Scanning [38] }\end{array}$ \\
\hline
\end{tabular}

\section{Summary}

The paper presents an approach to designing modular battery management systems that emphasize their energy efficiency and modularity. The developed low-power wireless communication interface for energy storage systems enables integrating more than a hundred battery modules and examining their status within ca. $10 \mathrm{~s}$. The average power required to supply the MBMS consisting of the master module and a hundred slave units operating in normal mode is equal to $0.5 \mathrm{~W}$. The estimated annual energy consumption accounts for $16 \%$ of the energy stored in the Li-Ion battery system with a rated capacity of $60 \mathrm{~mJ}$. This amount of energy is comparable to the self-discharge losses in Li-Ion cells and proves the high energy efficiency of the presented work. The application of a microcontroller and RF transceivers with a shorter initialization time might be considered to reduce energy consumption even further. Therefore, the proposed solution can significantly increase the efficiency of the entire system without loss of its functionality. The concept of the dedicated low power communication interface between modules presented in the paper seems to be particularly promising. It could probably be a solid basis for further development in the open-source formula or adaptation to other solutions, such as wireless sensor networks.

Author Contributions: Conceptualization, R.G.; methodology, R.G.; software, T.P.; validation, D.B.; formal analysis, D.B.; investigation, R.G. and T.P.; resources, D.B.; data curation, T.P. and R.G.; writing-original draft preparation, R.G. and T.P.; writing—review and editing, R.G. and T.P.; visualization, T.P.; project administration, D.B.; funding acquisition, D.B. All authors have read and agreed to the published version of the manuscript.

Funding: This research was funded by the National Centre for Research and Development of Poland (Grant No. POIR.01.02.00-00-0297/17-00).

Institutional Review Board Statement: Not applicable.

Informed Consent Statement: Not applicable.

Data Availability Statement: Not applicable.

Acknowledgments: This work was supported by the National Centre for Research and Development of Poland.

Conflicts of Interest: The authors declare that they have no known competing financial interests or personal relationships that could have appeared to influence the work reported in this paper.

\section{References}

1. Gür, T.M. Review of electrical energy storage technologies, materials and systems: Challenges and prospects for large-scale grid storage. Energy Environ. Sci. 2018, 11, 2696-2767. [CrossRef]

2. Placke, T.; Kloepsch, R.; Dühnen, S.; Winter, M. Lithium ion, lithium metal, and alternative rechargeable battery technologies: The odyssey for high energy density. J. Solid State Electrochem. 2017, 21, 1939-1964. [CrossRef] 
3. Meister, P.; Jia, H.; Li, J.; Kloepsch, R.; Winter, M.; Placke, T. Best Practice: Performance and Cost Evaluation of Lithium Ion Battery Active Materials with Special Emphasis on Energy Efficiency. Chem. Mater. 2016, 28, 7203-7217. [CrossRef]

4. Wu, C.; Lou, J.; Zhang, J.; Chen, Z.; Kakar, A.; Emley, B.; Ai, Q.; Guo, H.; Liang, Y.; Lou, J.; et al. Current status and future directions of all-solid-state batteries with lithium metal anodes, sulfide electrolytes, and layered transition metal oxide cathodes. Nano Energy 2021, 87, 106081. [CrossRef]

5. Schmuch, R.; Wagner, R.; Hörpel, G.; Placke, T.; Winter, M. Performance and cost of materials for lithium-based rechargeable automotive batteries. Nat. Energy 2018, 3, 267-278. [CrossRef]

6. Beard, K.W. Lithium secondary cells. In Linden's Handbook of Batteries, 5th ed.; McGraw-Hill Education: New York, NY, USA, 2019.

7. Andre, D.; Kim, S.-J.; Lamp, P.; Lux, S.F.; Maglia, F.; Paschos, O.; Stiaszny, B. Future generations of cathode materials: An automotive industry perspective. J. Mater. Chem. A 2015, 3, 6709-6732. [CrossRef]

8. Shobana, M.K. Metal oxide coated cathode materials for Li ion batteries-A review. J. Alloys Compd. 2019, 802, 477-487. [CrossRef]

9. Arroyo-de Dompablo, M.; Ponrouch, A.; Johansson, P.; Palacín, M. Achievements, Challenges, and Prospects of Calcium Batteries. Chem. Rev. 2019, 120, 6331-6357. [CrossRef]

10. Gummow, R.J.; Vamvounis, G.; Kannan, M.B.; He, Y. Calcium-Ion Batteries: Current State-of-the-Art and Future Perspectives. Adv. Mater. 2018, 30, 1801702. [CrossRef]

11. Yang, H.; Li, H.; Li, J.; Sun, Z.; He, K.; Cheng, H.-M.; Li, F. The Rechargeable Aluminum Battery: Opportunities and Challenges. Angew. Chem. Int. Ed. 2019, 58, 11978-11996. [CrossRef] [PubMed]

12. Mao, M.; Gao, T.; Hou, S.; Wang, C. A critical review of cathodes for rechargeable Mg batteries. Chem. Soc. Rev. 2018, 47, 8804-8841. [CrossRef]

13. Attias, R.; Salama, M.; Hirsch, B.; Goffer, Y.; Aurbach, D. Anode-Electrolyte Interfaces in Secondary Magnesium Batteries. Joule 2019, 3, 27-52. [CrossRef]

14. Warner, J. Chapter 8-Battery Management System Controls. Chapter 9-System Control Electronics. In The Handbook of Lithium-Ion Battery Pack Design; Elsevier: Ann Arbor, MI, USA, 2015; pp. 91-113. [CrossRef]

15. Stuart, T.A.; Zhu, W. Modularized battery management for large lithium ion cells. J. Power Sources 2011, 196, 458-464. [CrossRef]

16. Pastor-Fernández, C.; Bruen, T.; Widanage, W.D.; Gama-Valdez, M.A.; Marco, J. A Study of Cell-to-Cell Interactions and Degradation in Parallel Strings: Implications for the Battery Management System. J. Power Sources 2016, 329, 574-585. [CrossRef]

17. Sehil, K.; Alamri, B.; Alqarni, M.; Sallama, A.; Darwish, M. Empirical Analysis of High Voltage Battery Pack Cells for Electric Racing Vehicles. Energies 2021, 14, 1556. [CrossRef]

18. Rothgang, S.; Baumhöfer, T.; van Hoek, H.; Lange, T.; de Doncker, R.W.; Sauer, D.U. Modular battery design for reliable, flexible and multi-technology energy storage systems. Appl. Energy 2015, 137, 931-937. [CrossRef]

19. Soltani, A.K.; Kandidayeni, M.; Boulon, L.; St-Pierre, D.L. Modular Energy Systems in Vehicular Applications. Energy Procedia 2019, 162, 14-23. [CrossRef]

20. Cicconi, P.; Kumar, P.; Varshney, P. A support approach for the modular design of Li-ion batteries: A test case with PCM. J. Energy Storage 2020, 31, 101684. [CrossRef]

21. Wang, Y.; Tian, J.; Sun, Z.; Wang, L.; Xu, R.; Li, M.; Chen, Z. A comprehensive review of battery modeling and state estimation approaches for advanced battery management systems. Renew. Sustain. Energy Rev. 2020, 131, 110015. [CrossRef]

22. Dai, H.; Jiang, B.; Hu, X.; Lin, X.; Wei, X.; Pecht, M. Advanced battery management strategies for a sustainable energy future: Multilayer design concepts and research trends. Renew. Sustain. Energy Rev. 2021, 138, 110480. [CrossRef]

23. Kirchev, A. Chapter 20-Battery Management and Battery Diagnostics. In Electrochemical Energy Storage for Renewable Sources and Grid Balancing; Moseley, P.T., Garche, J., Eds.; Elsevier: Ulm, Germany, 2015; pp. 411-435. [CrossRef]

24. Julien, C.; Mauger, A.; Vijh, A.; Zaghib, K. Safety Aspects of Li-Ion Batteries. In Lithium Batteries: Science and Technology; Julien, C., Mauger, A., Vijh, A., Zaghib, K., Eds.; Springer International Publishing: Berlin/Heidelberg, Germany, 2016 ; pp. 549-583. [CrossRef]

25. Vetter, J.; Novák, P.; Wagner, M.R.; Veit, C.; Möller, K.-C.; Besenhard, J.O.; Winter, M.; Wohlfahrt-Mehrens, M.; Vogler, C.; Hammouche, A. Ageing mechanisms in lithium-ion batteries. J. Power Sources 2005, 147, 269-281. [CrossRef]

26. Gozdur, R.; Guzowski, B.; Dimitrova, Z.; Noury, A.; Mitukiewicz, G.; Batory, D. An energy balance evaluation in lithiumion battery module under high temperature operation. Energy Convers. Manag. 2021, 227, 113565. [CrossRef]

27. Ci, S.; Lin, N.; Wu, D. Reconfigurable Battery Techniques and Systems: A Survey. IEEE Access 2016, 4, 1175-1189. [CrossRef]

28. Steinhorst, S.; Shao, Z.; Chakraborty, S.; Kauer, M.; Li, S.; Lukasiewycz, M.; Narayanaswamy, S.; Rafique, M.U.; Wang, Q. Distributed reconfigurable Battery System Management Architectures. In Proceedings of the 21st Asia and South Pacific Design Automation Conference (ASP-DAC) 2016, Macao, China, 25-28 January 2016; pp. 429-434. [CrossRef]

29. Jiang, J.; Zhang, C. Technologies for the Design and Application of the Battery Management System. In Fundamentals and Applications of Lithium-Ion Batteries in Electric Drive Vehicles; Wiley: Singapore, 2015. [CrossRef]

30. Frost, D.F.; Howey, D.A. Completely Decentralized Active Balancing Battery Management System. IEEE Trans. Power Electron. 2018, 33, 729-738. [CrossRef]

31. Lee, A.I.; Lee, J.; Lee, M.; Chon, A. Wireless Battery Management System (WiBMS). In Proceedings of the 2013 World Electric Vehicle Symposium and Exhibition (EVS27), Barcelona, Spain, 17-20 November 2013; pp. 1-5.

32. Wu, Y.; Liao, X.; Chen, W.; Chen, D. A Battery Management System for electric vehicle based on Zigbee and CAN. 4th Int. Congr. Image Signal Process. 2011, 5, 2517-2521. [CrossRef] 
33. Alonso, D.; Opalko, O.; Sigle, M.; Dostert, K. Towards a Wireless Battery Management System: Evaluation of Antennas and Radio Channel Measurements Inside a Battery Emulator. In Proceedings of the 2014 IEEE 80th Vehicular Technology Conference (VTC2014-Fall), Vancouver, BC, Canada, 14-17 September 2014.

34. Shell, C.; Henderson, J.; Verra, H.; Dyer, J. Implementation of a wireless battery management system (WBMS). In Proceedings of the 2015 IEEE International Instrumentation and Measurement Technology Conference (I2MTC) Proceedings, Pisa, Italy, 11-14 May 2015.

35. The European Table of Frequency Allocations and Applications in the Frequency Range $8.3 \mathrm{kHz}$ to $3000 \mathrm{GHz}$ (ECA TABLE), European Communications Office Rev. Appr. 2020. Available online: https: / / www.google.com/url? sa=t\&rct=j\&q=\&esrc=s\& source=web\&cd=\&ved=2ahUKEwj3muLzzKvzAhXjkIsKHdnMCGgQFnoECAYQAQ\&url=https\%3A\%2F\%2Fdocdb.cept.org\% 2Fdownload\%2F2051\&usg=AOvVaw3ehiyy0EgEPCqw7m_wVU4V (accessed on 30 August 2021).

36. Narayanaswamy, S.; Schlueter, S.; Steinhorst, S.; Lukasiewycz, M.; Chakraborty, S.; Hoster, H. On Battery Recovery Effect in Wireless Sensor Nodes. ACM Trans. Des. Autom. Electron. Syst. 2016, 21, 1-28. [CrossRef]

37. LTC5800-IPM Datasheet. Available online: https://www.analog.com/media/en/technical-documentation/data-sheets/5800 ipmfa.pdf (accessed on 30 August 2021).

38. Hortelano, D.; Olivares, T.; Ruiz, M.C. Reducing the energy consumption of the friendship mechanism in Bluetooth mesh. Comput. Netw. 2021, 195, 108172. [CrossRef]

39. Darroudi, S.M.; Caldera-Sànchez, R.; Gomez, C. Bluetooth Mesh Energy Consumption: A Model. Sensors 2019, 19, 1238. [CrossRef] 